\title{
Addressing Social Security's Solvency While Promoting High Labor Force Participation
}

\author{
John Laitner
}

Project \#: R-UM18-10 


\title{
Addressing Social Security's Solvency While Promoting High Labor Force Participation
}

\author{
John Laitner \\ University of Michigan \\ October 2018 \\ Michigan Retirement Research Center \\ University of Michigan \\ P.O. Box 1248 \\ Ann Arbor, MI 48104 \\ www.mrrc.isr.umich.edu \\ (734) 615-0422
}

\section{Acknowledgements}

The research reported herein was performed pursuant to a grant from the U.S. Social Security Administration (SSA) funded as part of the Retirement Research Consortium through the University of Michigan Retirement Research Center Award RRC08098401-10. The opinions and conclusions expressed are solely those of the author(s) and do not represent the opinions or policy of SSA or any agency of the federal government. Neither the United States government nor any agency thereof, nor any of their employees, makes any warranty, express or implied, or assumes any legal liability or responsibility for the accuracy, completeness, or usefulness of the contents of this report. Reference herein to any specific commercial product, process or service by trade name, trademark, manufacturer, or otherwise does not necessarily constitute or imply endorsement, recommendation or favoring by the United States government or any agency thereof.

\section{Regents of the University of Michigan}

Michael J. Behm, Grand Blanc; Mark J. Bernstein, Ann Arbor; Shauna Ryder Diggs, Grosse Pointe; Denise Ilitch, Bingham Farms; Andrea Fischer Newman, Ann Arbor; Andrew C. Richner, Grosse Pointe Park; Ron Weiser, Ann Arbor; Katherine E. White, Ann Arbor; Mark S. Schlissel, ex officio 


\title{
Addressing Social Security's Solvency While Promoting High Labor Force Participation
}

\begin{abstract}
A number of proposals and options to address OASI trust-fund solvency have been suggested in recent years. The present work attempts to examine solvency-promoting reforms from the standpoint of economic efficiency - that is, from the perspective of their effect on household and societal well-being. Ultimately, we argue that solvency and efficiency should be joint considerations for policy. We first set up a structural model of household consumption/saving and retirement choices. We estimate the model's parameters using Consumer Expenditure Survey and Health and Retirement Study data. Then we simulate policy changes. Using the 2017 Social Security Trustee's Report, we examine policy changes that could prevent trust fund depletion for 75 years or more. In the simulations, payroll tax increases or Social Security benefit reductions sufficient to ensure solvency have modest effects on household labor supply, though they lower lifetime consumption and utility. Earlier work considered age-targeted payroll tax changes that could promote longer careers. Here, we examine possible changes to the Social Security benefit formula - specifically the AIME formula - that could encourage delayed retirement more straightforwardly. We show that incentivizing an extra one to two years of work on average might be possible. That would generate substantial new tax revenues, from both payroll and income taxes. Although sacrificed leisure would lead to household utility reductions, they are relatively small - comparable to the best alternatives. Comparing the results with simpler tax and benefit changes, we suggest that promoting longer careers could enlarge the set of policy options in a useful way.
\end{abstract}

\section{Citation}

Laitner, John. 2018. “Addressing Social Security’s Solvency While Promoting High Labor Force Participation," Ann Arbor MI: University of Michigan Retirement Research Center (MRRC) Working Paper, WP 2018-386. https://mrdrc.isr.umich.edu/publications/papers/pdf/wp386.pdf 


\section{Introduction}

Policymakers have developed a number of proposals and options to address solvency concerns about the OASI and DI Trust Funds. Questions arise, however, about the full spectrum of possible implications of each given proposed policy. This paper focuses on the potential consequences for economic efficiency of different courses of action. Specifically, we use a structural economic model to study the likely behavioral responses of households to various policies, with our interest centering on whether a particular policy encourages households to work longer or, conversely, to retire earlier.

The basic idea of this paper is as follows. As a household makes its decision of when to retire, it should, at its chosen retirement age, perceive the extra remuneration from working one more month to exactly offset the disutility of lost leisure from delaying retirement by the same amount. This might seem to imply that a policy change that encouraged more work would provide little net gain to households. We need, however, to recognize that existing income and payroll taxes mean a household's private gain from work tends to be smaller than the social gain — with the latter being the sum of the personal gain and the increase in tax revenue for society. ${ }^{1}$ Put another way, in deciding when to retire, a household balances its net-of-tax earnings from more work against the benefit of increased leisure from retirement. Society's gain if the household works longer is, however, the grossof-tax wage. Taxes thus create a wedge that, in turn, leaves scope for encouraging longer careers to promote efficiency. Extra tax revenues may be generated, and we attempt to assess how large they might be.

Our analysis uses a structural model with parameters estimated from HRS data. The 2017 Social Security Trustee's Report predicts the OASDI trust fund will be depleted by 2034, and an immediate, permanent payroll tax increase of $2.76 \%$ (an increase of about $22.26 \%$ ) or an immediate, permanent benefit reduction of $17 \%$ will be required to achieve full solvency for 75 years. Using round numbers, we simulate a $24 \%$ payroll tax increase and an $18 \%$ benefit reduction, accordingly. In the simulations, either policy has a modest effect on labor supply. We also consider a modification to the indexing formula for calculating the Social Security benefits. The modification increases incentives to delay retirement. Simulations show that increases in the average retirement age of 1-2 years are possible, that corresponding increases in income and payroll tax revenues could cover $1 / 4$ to $1 / 3$ of the shortfall in the Trustee's Report, and that utility losses would be less than those from payroll tax increases with the same revenue enhancement. We examine the distributional impacts of the 3 approaches as well. The analysis suggests that policies that promote

1 This assumes that a household's access to public goods is independent of the taxes it pays. 
longer careers could be a useful component of reforms designed to ensure Social Security's long-term solvency.

\section{Literature}

A large literature studies the effects of Social Security on labor supply (see, for example, Feldstein and Liebman [2002]). Here, we are specifically interested in reforms that could improve the solvency outlook for Social Security. A structural model allows the study of counterfactuals. We use such a model, estimating its parameters from HRS and other data (e.g., Gustman and Steinmeier [1986], Rust and Phelan [1997], French [2005]). We simulate (i) payroll tax increases and (ii) OASI benefit reductions. We examine impacts on labor supply and household well-being. We then turn our attention to (iii) policies designed to increase labor force participation. We ask whether they could contribute to solvency. A literature on age-dependent taxes suggests targeting lower tax rates at household with more elastic labor supply (see, for instance, Banks and Diamond [2010]). In that vein, several papers consider lowering taxes on labor income as households reach the normal age of retirement (e.g., Goda et al [2009], Burtless and Quinn [2002], Laitner and Silverman (LS) $[2012,2017])$. The present analysis is related to the later work, comparing option (iii) with (i)-(ii).

LS [2012, 2017] study a reform that would raise the payroll tax on young adults but lower it on those in their late 50 s or early $60 \mathrm{~s}$. The idea is to raise the net-of-tax remuneration at ages when households reach the margin of retirement. LS [2017] suggest that increases in the average retirement age of 1-1.5 years might be possible. However, the reform would be elaborate. And, the distributional effects could be substantial. Here, we consider a simpler policy. Its potential contribution to Social Security solvency would be extra tax revenues from longer work lives.

\section{Model}

We use a structural economic model, with parameters estimated from HRS and linked Social Security earnings-record data.

Each household seeks to adjust its lifetime trajectory of consumption expenditure to maximize its lifetime utility, subject to its budget constraints. A household's basic resources consist of the (net-of-tax) labor earnings of its adult male and female, and Social Security benefits. In addition to choosing its trajectory of consumption/saving, a household picks its retirement age. In this paper, female earnings are taken to be exogenous and household retirement is retirement of the male adult. Labor supply is discrete households have latitude for choice on the extensive margin (i.e., retirement age) but not the intensive margin (i.e., how many hours per day to work). ${ }^{2}$

The economic unit is the household. Numbers of children, age of marriage, and life spans are exogenous. We adjust for household composition changes using "equivalent adult" indices, with estimated weights (see below). Labor earning profile shapes with respect to experience are exogenous, though they depend upon education (itself taken to

2 See, for example, Rust and Phelan [1997, p.786] and Hurd [1996]. 
be exogenous). As we solve the model for the optimal age of retirement and the optimal lifetime trajectory of household consumption, the analysis determines the age-path of household wealth accumulation. The model is homothetic, so that it can be applied to households from different birth cohorts: as improvements of technology lead to higher wages for more recent cohorts, their consumption and savings tend to rise proportionately, and their retirement age tends to remain unchanged. Changes in earnings profile shapes (as with rising educational attainments), as well as longer life spans, can, however, affect optimal retirement ages.

The structural model's framework comes from LS [2012]. Utility (per "equivalent adult") depends upon per capita consumption expenditure, say, $x_{s}$ at (household) age $s$, and per capita leisure, say, $s$. A household's utility flow, per equivalent adult, at age $s$ is

$$
u_{s}= \begin{cases}{\left[f_{s}\right]^{\bar{\gamma}} / \bar{\gamma},} & \text { for } \bar{\gamma}<1 \text { and } \bar{\gamma}=0, \\ \ln \left(f_{s}\right), & \text { for } \bar{\gamma}=0,\end{cases}
$$

with

$$
f_{s}=\left[x_{s}\right]^{\alpha} \cdot[s]^{1-\alpha}, \quad \alpha \in(0,1) .
$$

Let the age of retirement be $R$. Because labor supply is all-or-nothing, we normalize ${ }_{s}=1$ for $s<R$ and ${ }_{s}=\bar{\ell}>1$ for $s \geq R$. Setting $\gamma \equiv \bar{\gamma} \cdot \alpha$, we can rewrite (1)-(2) as

$$
u\left(x_{s}, s\right)= \begin{cases}{\left[x_{s}\right]^{\gamma} / \gamma,} & \text { for } s<R, \\ {\left[\omega \cdot x_{s}\right]^{\gamma} / \gamma,} & \text { for } s \geq R,\end{cases}
$$

where

$$
\omega \equiv[]^{\frac{1-\alpha}{\alpha}}>1
$$

If $N_{s}$ is the number of equivalent adults in the household at age $s$ and $X_{s}$ total household consumption expenditure, a household's age- $s$ utility flow is

$$
U\left(X_{s}, s\right)= \begin{cases}\frac{1}{\gamma} \cdot\left[\frac{X_{s}}{N_{s}}\right]^{\gamma}, & \text { for } s<R, \\ \frac{1}{\gamma} \cdot\left[\frac{\omega \cdot X_{s}}{N_{s}}\right]^{\gamma}, & \text { for } s \geq R .\end{cases}
$$

One necessary condition for optimality equates the marginal utility of a dollar spent on consumption before and after retirement. Letting $X_{R-}$ be expenditure the instant before retirement, we have ${ }^{3}$

$$
U_{1}\left(X_{R-}, R\right)=U_{1}\left(X_{R}, R\right) .
$$

3 We use the notation

$$
U_{1}(X, R) \equiv \partial U(X, R) / \partial X
$$


Algebra shows that (6) holds if and only if

$$
X_{R}=\Omega \cdot X_{R-} \quad \text { where } \quad \Omega \equiv[\omega]^{\frac{\gamma}{1-\gamma}} .
$$

A second necessary condition equates the gain from delaying retirement with the loss. The gain includes $U\left(X_{R-}, R\right) d R$ less the value of resources expended, $U_{1}\left(X_{R-}, R\right) \cdot X_{R-} d R$, plus increased Social Security benefits and earnings, $U_{1}\left(X_{R-}, R\right) \cdot\left[B(R) \cdot e^{r \cdot R}+y(R-)\right]$, where $B(R)$ is the present value at age 0 of a household's OASI benefits if it retires at age $R$. Similarly for the losses. We have

$$
\begin{aligned}
& U\left(X_{R-}, R\right)-U_{1}\left(X_{R-}, R\right) \cdot X_{R-}+U_{1}\left(X_{R-}, R\right) \cdot\left[B(R) \cdot e^{r \cdot R}+y(R-)\right]= \\
& U\left(\omega \cdot X_{R}, R\right)-U_{1}\left(\omega \cdot X_{R}, R\right) \cdot \omega \cdot X_{R} .
\end{aligned}
$$

Algebra and (6)-(7) enable us to simplify (8) to

$$
\frac{B(R) \cdot e^{r \cdot R}+y(R-)}{X_{R-}}=\frac{1-\gamma}{\gamma} \cdot[\Omega-1] .
$$

Expression (9), the first-order condition for the optimal retirement age, plays a key role throughout the analysis. On the left-hand side, we have the financial gain in Social Security benefits and earnings from the marginal year of work, converted to units of utility through multiplication by the marginal utility per dollar of consumption at the age of retirement. On the right, we have the sacrifice of leisure from the marginal year of work, also measured in units of utility. If we make the numerator on the left-hand side larger, the household desires to delay its retirement; if we make the denominator larger, marginal utility from consumption is lower, so it wishes to retire sooner. Either raising the household's current after-tax earnings or increasing the sensitivity of its Social Security benefits to its retirement age makes it want to work longer — whereas the higher the household's consumption, the greater its relative valuation of leisure, hence the greater its urge to retire.

Note that our formulation highlights the role of leisure. Retirees have more leisure and that may affect not only their well-being but also their intertemporal expenditure allocation. A household aggregates its current consumption expenditure and leisure into "service flow" $f_{s}$, which then determines its utility. Specification (2) makes consumption expenditure and leisure complementary in the production of services. If households are flexible about re-allocating service flows across ages, they will want high consumption expenditure during retirement, when it can be combined with high leisure. If, in contrast, households are rigid in wanting nearly equal service flows at all ages, they will plan for less consumption expenditure after retirement - using higher consumption expenditure during pre-retirement years to compensate themselves for limited leisure. A household's tolerance for intertemporal tradeoffs depends on the elasticity of intertemporal substitution, $1 /(1-$ $\gamma$ ). Marginal condition (6) shows that optimal consumption expenditure will "jump" up after retirement if $\gamma \in(0,1)$, that is to say if $1 /(1-\gamma)>1$, but it will jump down if $\gamma<0$, which implies $1 /(1-\gamma)<1$. 
Our specification enables us to estimate $\gamma$ and $\omega$ - see below. We can then gauge the contribution of leisure time to the well-being of retired households. And, the forecasted change in consumption at retirement - as dictated by (6) — will affect how much saving younger households should optimally undertake. Furthermore, the magnitude of the change in consumption expenditure at retirement can help to identify the value of $\gamma$ in the estimation.

Analysis of the complete model is more complicated than one might expect. As a household maximizes its lifetime utility with respect to its trajectory of consumption expenditure, it faces a standard, concave problem. We also have a convenient first-order condition, (9), for the household's optimal retirement age, say, $R^{*}$. However, the utilitymaximizing retirement age depends on the shape of the household's lifetime earnings profile. The retirement problem can easily, therefore, be non-concave. For instance, businesscycle fluctuations or episodic changes in the aggregate economic growth rate, promotions gained/or missed, and/or health changes can make a household's lifetime earnings profile choppy. Checking for local maxima, we find that multiple critical points do arise in some cases. When they do, we attempt to evaluate all and pick the one generating the highest lifetime utility.

\section{Data and Estimation}

Our parameter estimates come from LS [2017], as reproduced in Table 1. We have a 3-equation system. For the first equation, we use a synthetic panel from the consumer expenditure survey (CEX) 1984-2001 to estimate the parameters

$$
\left(\beta_{1}, \beta_{2}, \beta_{3}, \beta_{4}\right) \equiv \frac{r-\rho}{1-\gamma}, \xi^{S}, \xi^{K}, \frac{\gamma}{1-\gamma} \cdot \ln (\omega)
$$

where $\rho$ is the household subjective discount rate, $r$ is the interest rate, $\xi^{S}$ is the equivalent adult consumption weight for a spouse and $\xi^{K}$ is the same for a child, and $\omega$ is as in (7). Appendix 1 provides details (see also LS [2012]).

For the second and third regression equations, we use HRS demographic and linked Social Security earnings record data. We use panel data 1992-2014 from the original HRS cohort, which was age 51-61 in 1992. We use once-married households that are married in 1992. Both spouses have linked Social Security earnings histories. We estimate separate earnings dynamics equations for men and for women, dividing the samples into 4 different educational groups (less than high school, high school, some college, and college/more). We use the latter equations to impute earnings above the Social Security cap. We carry estimated "individual effects" from the earnings equations to the structural model of household behavior. The HRS survey data supplies detailed demographic information for each household. In addition to the linked earnings records, the HRS is well-known for its networth data, which includes not only financial assets and housing equity, but also detailed treatment of IRAs, defined benefit pension accounts, and estimates of the present value of defined benefit pension rights. (Our analysis of networth uses data from 1992 and excludes households already retired at that date.)

We solve each household's dynamic optimization problem using the parameters from (10). Our second regression equation relates a household's optimal retirement age to the 
value of $\gamma$. Call the estimate of the latter $\gamma^{R}$. The third regression equation solves for the optimal retirement age but uses it to determine the household's 1992 networth. The latter is its dependent variable, leading to an alternative estimate of $\gamma$, which we call $\gamma^{A}$. In theory, we should find $\gamma^{R}=\gamma^{A}$. In practice, they indeed are not significantly different. Our "stage-2" estimation imposes $\gamma=\gamma^{R}=\gamma^{A}$ (with our 3-equation system now over-identified). This paper uses the parameter estimates from Table 1, column 2.

We assume the gross-of-tax real interest rate is $5 \% / \mathrm{yr}$. This reflects the marginal product of physical capital in the U.S. economy (see Laitner and Silverman [2005]). ${ }^{4}$ For simplicity, we assume all men die at age 74 and all women at 80 .

Interpretation. Consider the parameter estimates of Table 1, column 2.

As noted in the Appendix, optimal pre-retirement life-cycle consumption per equivalent adult rises at rate $\beta_{1}=(r-\rho) /(1-\gamma)$. With $\beta_{1}=0.0272$, in the 40 years from, say, age 22 to 62 , it would, therefore, nearly triple (presumably manifested, in practice, in larger living space, fancier automobiles, etc.).

The parameters $\beta_{2}=0.3351$ and $\beta_{3}=0.3373$ imply that a household allocates more consumption expenditure to years with 2 adults than 1, and more to periods with resident children. However, estimates of both $\beta_{2}$ and $\beta_{3}$ are significantly less than 1 - implying substantial economies of scale in household size. ${ }^{5}$

The parameter $\beta_{4}$ is novel to our modeling specification. Its magnitude implies that a household will plan to reduce its consumption expenditure after retirement by about $9.2 \%$. In other words, households will want to compensate themselves for less leisure prior to retirement with higher consumption spending. However, the effect seems modest. ${ }^{6}$

The intertemporal elasticity of substitution (IES), $1 /(1-\gamma)$, is about 0.82 . This is within the standard range in the literature, though at the range's higher end (LS [2012]). It implies that households are willing to shift their consumption spending fairly vigorously in response to, for instance, interest rate changes.

Features of the Analysis. One innovation of our approach is the nonseparability of its utility function in consumption and leisure. As described above, that enables us to study the possible complementarities of consumption and leisure, including potential implications of abrupt consumption changes at retirement. Second, this paper's model is fully identified on the basis of either retirement or networth data. Thus, Table 1, column 1, can estimate the key IES parameter separately from each and test for equality.

Finally, noting potential problems with local maxima in the solution for the optimal retirement age, we employ an estimation algorithm that checks for the optimal retirement age in each 1-year interval for ages 50-74. In the estimation, calculations find local maxima in $5-10 \%$ of the cases.

4 This is a compromise choice: in practice, bank accounts and money market funds tend to pay less than 5\%/yr; common stocks and mortgages more; and, credit card debt even more.

5 See the comparisons with the literature in LS [2012], for example.

6 Earlier papers in the literature suggested much steeper declines after retirement, but the estimates in Table 1 resemble more recent results — see the discussion in LS [2012]. 


\begin{tabular}{|c|c|c|}
\hline \multicolumn{3}{|c|}{$\begin{array}{l}\text { Table 1. Structural Model Regression Outcomes: } \\
\text { Estimated Parameter (Std. Error/T-Stat.) }\end{array}$} \\
\hline variable & Stage 1 & Stage 2 \\
\hline$\beta_{1}=\frac{r-\rho}{1-\gamma}$ & $\begin{array}{c}0.0264^{* * *} \\
(0.0008 / 34.5727)\end{array}$ & $\begin{array}{c}0.0272^{* * *} \\
(0.0006 / 41.9929)\end{array}$ \\
\hline$\beta_{2}=\xi^{S}$ & $\begin{array}{c}0.3351^{* * *} \\
(0.0523 / 6.4108)\end{array}$ & $\begin{array}{c}0.3351^{* * *} \\
(0.0491 / 6.8244)\end{array}$ \\
\hline$\beta_{3}=\xi^{K}$ & $\begin{array}{c}0.3372^{* * *} \\
(0.0181 / 18.6690) \\
\end{array}$ & $\begin{array}{c}0.3373^{* * *} \\
(0.0165 / 20.4231) \\
\end{array}$ \\
\hline$\beta_{4}=\frac{\gamma}{1-\gamma} \cdot \ln (\omega)$ & $\begin{array}{c}-0.0831^{* *} \\
(0.0370 /-2.2482) \\
\end{array}$ & $\begin{array}{c}-0.0830^{* * *} \\
(0.0218 /-3.8153) \\
\end{array}$ \\
\hline$\gamma$ & NA & $\begin{array}{c}-0.2171^{* * *} \\
(0.0245 /-8.8703)\end{array}$ \\
\hline$\gamma^{R}$ & $\begin{array}{c}-0.2179^{*} \\
(0.1150 /-1.8940)\end{array}$ & $\mathrm{NA}$ \\
\hline$\gamma^{A}$ & $\begin{array}{c}-0.0906^{* *} \\
(0.0449 /-2.0179) \\
\end{array}$ & NA \\
\hline Observations & 4033 & 4033 \\
\hline Criterion $\mathcal{S}(\theta, \hat{V})$ & 0.0000 & 11.6044 \\
\hline \multicolumn{3}{|c|}{ Wald Test of Hypothesis $\gamma^{R}=\gamma^{A}$} \\
\hline$\gamma^{R}-\gamma^{A}$ & $\begin{array}{c}-0.1273 \\
(0.0816 /-1.5595)\end{array}$ & NA \\
\hline
\end{tabular}

Source: see text. Significant ${ }^{*} 10 \%,{ }^{* *} 5 \%,{ }^{* * *} 1 \%$ level.

\section{Policy}

As previewed in the introduction, the Social Security Trustee's Report 2017 projects that restoring Trust Fund solvency would require an immediate, permanent payroll tax increase of about 24\%, an immediate, permanent cut in Social Security benefits of about $18 \%$, or some combination of the two. This section simulates changes of these types. We are especially interested in the model's forecasted labor-supply reactions and the effects on household well-being.

In our simulations, household demographics and lifetime earnings profile shapes are as in the HRS data, as are interest rates. We assume a gross-of-tax real interest rate of $5 \% / \mathrm{yr}$. Our simulations assume that new taxes or benefits apply to HRS couples throughout their 
lives. We do not study transitions for the economy between balanced growth paths. Rather, we compare different long-run growth paths. Although the model is partial equilibrium in nature - taking wages and interest rates as exogenous - it describes household actions in terms of optimizing lifetime saving/consumption profiles and (male) retirement age; thus, it can capture household responses to policy changes.

Payroll Taxes. Table 2 examines payroll tax increases. We consider increases of 6, 8, 12,16 , and $24 \%$ of the 2015 OASI tax. In each simulation, we add that amount to the payroll tax. ${ }^{7}$ The simulations leave the Social Security earnings cap and benefit formula at historical levels. Until the separate section on distributional effects below, we focus on the top 5 rows of the table.

To develop intuitions, consider (9). Table-2 policies leave the condition's right-hand side unchanged. On the left, OASI benefits are unchanged, but $y(R-)$, net-of-tax earnings just prior to retirement, decreases. If a household's total lifetime resources decreased by the percent of the tax increase - and $B(R) \cdot e^{r \cdot R}$ is small - household consumption as retirement approaches, $X_{R-}$, would drop the same percentage, and $R$ would remain the same. In other words, the income and substitution effects of the tax increase would exactly counterbalance one another. In practice, however, $B(R) \cdot e^{r \cdot R}$ is positive and $y(R-)$ will drop less in percentage than the tax increase when the Social Security cap is binding. In

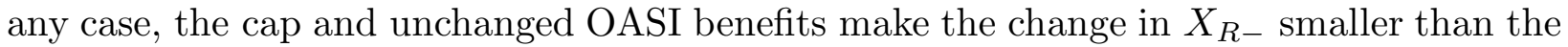
percent payroll tax change. Thus, we expect the change in $R$ to be near, but not exactly equal to, 0 .

Table 2 bears the intuitions out. If we raise the payroll tax by $24 \%$, the average retirement age changes only about 1.5 months (i.e., $13 \%$ of a year). Although the tax increase is about 2.5\%, earnings above the OASI cap and Social Security benefits are unaffected; so, the lifetime profile of per capita (adult) consumption only declines by $2 \%$.

OASI Benefits. $\quad$ Table 3 considers reductions of 4.5, 6, 9, 12, and $18 \%$ in OASI benefits. As above, we first concentrate on the top 5 rows of the table.

Again, consider (9). The right-hand side is unchanged. On the left, $B(R) \cdot e^{r \cdot R}$ will decrease because benefits are smaller. In general, however, the $B(R)$ term is small - see below. The term $y(R-)$ is unaffected. Smaller OASI benefits reduce a household's lifetime resources, so $X_{R-}$ will fall. Thus, households should tend to choose less leisure, causing $R$ to increase. In this case, we have an almost pure income effect.

Though Table 3 bears out the predicted sign of the change in $R$, the magnitude of the change is relatively small. Without an offsetting substitution effect, we might expect the (negative) income effect to produce a hefty decline in the average retirement age. One explanation for the modest effect that we find is that OASI benefits arrive late in a household's life; hence, in present value terms, their impact is smaller than otherwise. The Social Security system operates on a pay-as-you-go basis, with payroll taxes from workers contemporaneously funding benefits to retirees. For a household, in contrast to the Social Security system, taxes precede benefits. With a $5 \% /$ yr gross interest rate, the difference

7 For the fifth row of Table 2 , for example, we add $0.106 \times 0.24=0.02544$ to each year's payroll tax rate. Since the payroll tax was lower early in the careers of the HRS cohort, the percentage changes in the simulations were higher at those ages. 


\section{Table 2. Simulated Change in Average Retirement Age after Payroll Tax Increase}

\begin{tabular}{|c|c|c|c|c|}
\hline $\begin{array}{c}\text { Payroll Tax } \\
\text { Change } \\
(\%)\end{array}$ & $\begin{array}{c}\text { Change } \\
\text { Retirement } \\
\text { Age (Yrs) }\end{array}$ & $\begin{array}{c}\text { Change } \\
\text { Consumption } \\
\text { Per Capita }(\%)\end{array}$ & $\begin{array}{c}\text { Change } \\
\text { Utility } \\
(\%)\end{array}$ & $\begin{array}{c}\text { Change } \\
\text { OASI } \\
\text { Benefit }(\%)\end{array}$ \\
\hline \multicolumn{5}{|c|}{ All Once-Married Couples (1634 Observations) } \\
\hline 6.00 & -0.03 & -0.51 & -0.11 & -0.01 \\
\hline 8.00 & -0.04 & -0.68 & -0.14 & -0.01 \\
\hline 12.00 & -0.07 & -1.02 & -0.22 & -0.02 \\
\hline 16.00 & -0.09 & -1.36 & -0.29 & -0.03 \\
\hline 24.00 & -0.13 & -2.04 & -0.44 & -0.05 \\
\hline \multicolumn{5}{|c|}{ Couples with High School Educated Male (565 Observations) } \\
\hline 6.00 & -0.03 & -0.54 & -0.11 & -0.01 \\
\hline 8.00 & -0.04 & -0.72 & -0.15 & -0.01 \\
\hline 12.00 & -0.08 & -1.08 & -0.23 & -0.02 \\
\hline 16.00 & -0.09 & -1.44 & -0.31 & -0.02 \\
\hline 24.00 & -0.14 & -2.16 & -0.46 & -0.03 \\
\hline \multicolumn{5}{|c|}{ Couples with College Educated Male (429 Observations) } \\
\hline 6.00 & -0.03 & -0.42 & -0.09 & -0.02 \\
\hline 8.00 & -0.04 & -0.56 & -0.12 & -0.02 \\
\hline 12.00 & -0.06 & -0.84 & -0.18 & -0.03 \\
\hline 16.00 & -0.08 & -1.12 & -0.24 & -0.04 \\
\hline 24.00 & -0.12 & -1.68 & -0.36 & -0.07 \\
\hline
\end{tabular}

Source: see text. Simulations based on the original HRS cohort in all cases.

in timing is significant. The Trustee's Report shows an OASI benefit cut of $18 \%$ helps the Social Security Trust Fund roughly as much as a payroll tax increase of $24 \%$, but from a household's perspective the two policies are quite different.

A comparison of the consumption and utility changes in Tables 2-3 shows that the loss from a $24 \%$ tax increase is about twice that of an $18 \%$ benefit reduction. That would be consistent with the fact that that the benefit reduction induces virtually no distorting substitution effect and/or that the timing difference for the 2 policies makes the second less onerous.

Summary of Tables 2-3. Our model allows us to study household reactions to policy changes, as labor supply and consumption decisions are determined by utility-maximizing behavior. In effect, we do "dynamic," as opposed to "static scoring." For policies of the magnitude needed to restore Trust Fund solvency, however, household reactions evident in both Tables 2 and 3 turn out to be modest.

That does not necessarily imply that underlying economic inefficiencies are small. In (9), the wedge between gross and net earnings created by OASI payroll and federal income 


\section{Table 3. Simulated Change in Average Retirement Age after OASI Benefit Decrease}

\begin{tabular}{|c|c|c|c|c|}
\hline $\begin{array}{c}\text { OASI Benefit } \\
\text { Change } \\
(\%) \\
\end{array}$ & $\begin{array}{c}\text { Change } \\
\text { Retirement } \\
\text { Age (Yrs) } \\
\end{array}$ & $\begin{array}{c}\text { Change } \\
\text { Consumption } \\
\text { Per Capita }(\%) \\
\end{array}$ & $\begin{array}{c}\text { Change } \\
\text { Utility } \\
(\%)\end{array}$ & $\begin{array}{c}\text { Change } \\
\text { OASI } \\
\text { Benefit }(\%) \\
\end{array}$ \\
\hline \multicolumn{5}{|c|}{ All Once-Married Couples (1634 Observations) } \\
\hline 4.50 & 0.02 & -0.26 & -0.06 & -4.50 \\
\hline 6.00 & 0.02 & -0.34 & -0.08 & -6.00 \\
\hline 9.00 & 0.03 & -0.51 & -0.11 & -9.00 \\
\hline 12.00 & 0.04 & -0.68 & -0.15 & -12.00 \\
\hline 18.00 & 0.07 & -1.02 & -0.23 & -18.00 \\
\hline \multicolumn{5}{|c|}{ Couples with High School Educated Male (565 Observations) } \\
\hline 4.50 & 0.02 & -0.26 & -0.06 & -4.50 \\
\hline 6.00 & 0.03 & -0.34 & -0.08 & -6.00 \\
\hline 9.00 & 0.04 & -0.52 & -0.12 & -9.00 \\
\hline 12.00 & 0.05 & -0.69 & -0.16 & -12.00 \\
\hline 18.00 & 0.08 & -1.03 & -0.23 & -18.00 \\
\hline \multicolumn{5}{|c|}{ Couples with College Educated Male (429 Observations) } \\
\hline 4.50 & 0.00 & -0.23 & -0.05 & -4.50 \\
\hline 6.00 & 0.01 & -0.31 & -0.07 & -6.00 \\
\hline 9.00 & 0.01 & -0.46 & -0.10 & -9.00 \\
\hline 12.00 & 0.01 & -0.61 & -0.14 & -12.00 \\
\hline 18.00 & 0.03 & -0.91 & -0.20 & -18.00 \\
\hline
\end{tabular}

Source: see text. Simulations based on the original HRS cohort in all cases.

taxes together can easily be $25 \%$ or more. Although the $B(R) \cdot e^{r \cdot R}$ term could provide a counterbalance, in the examples it does not: in our baseline simulation utilizing all couples, the average $B(R) \cdot e^{r \cdot R}$ is $\$ 616$, whereas the average $y(R-)$ is $\$ 19,250$, and the average tax wedge is $\$ 7113$ (all 3 measured in 1984 dollars).

Retirement Incentives Within Social Security. This section examines the OASI work incentive term from $(9), B(R) \cdot e^{r \cdot R}$, in more detail. The next section then suggests a third policy for bolstering revenues for the OASI trust fund.

In principle, the Social Security benefit formula encourages labor-force participation. Consider an individual's benefit calculation, say, in the year 2000. The full retirement age was 65. The individual's "indexing year" is the year he/she turned 60. Create a vector of earnings for the individual. For ages past 60, include current earnings, up to the year's Social Security cap. For each earlier age $s$, multiply earnings (up to that year's cap) by the average Social Security wage in the indexing year divided by the average Social Security wage in year the individual was age $s$. Then select the highest 35 elements in the vector, sum them, and divide by $35 \times 12$. That yields the individual's "average indexed 
monthly earnings" (AIME). Apply the Social Security system benefit formula to the AIME. Although the benefit formula is progressive, it is increasing in the AIME. A longer career provides more elements from which to select the top 35. Hence, there is an incentive to work longer.

In fact, the latter incentive will tend to be weak for many households. Recall, for instance, the dollar values at the end of the last section. An important reason for the weak effect is the indexing process. The scaling factor in the indexing procedure reflects the growth of nominal wages - in other words, both inflation and TFP advances. In practice, the magnitude of the re-scaling tends to be large. For example, the factor applied to 1951 earnings for an individual turning 60 in 1991 was about 7.5. Given indexation, a male HRS lifetime earnings profile tends to resemble the solid curve in Diagram 1. It rises at early ages, reflecting accumulation of experiential human capital. After reaching a peak, it falls, perhaps due to declining health status. A household starting work at 22 and contemplating retirement at 62 , for illustration, has 40 years of earnings. The household could exclude 5 years in computing its AIME. In the diagram, the household would drop earnings for ages 22-26. If the household considered delaying retirement to age 63, it could also drop $y(27)$, using $y(63)$ as a replacement. But, in the pictured case, the gain to the AIME from the last step would be modest.

Promoting Longer Careers. Table 4 examines the effect of eliminating indexing. Begin with the table's top panel.

As we eliminate indexation, we switch to the dashed curve in Diagram 1. It is much steeper. If our individual above considers working one more year after age 62 , the contribution to his/her AIME will be a number of times larger. On the other hand, the level of everyone's AIME will be considerably smaller because the dashed curve is lower at all ages before 60 . Thus, our simulations multiply all earnings by a constant, say, $z$, that preserves the average AIME from before - without changing proportionate incentives from the dashed curve.

The retirement-age outcomes from removing indexation in Table 4 are much larger than what we find in Tables 2-3. In row 1, Table 4, for example, removing indexation delays retirement by an average of 1.27 years. In row 2 , we not only discontinue indexation but also let households count each year's earnings for ages $\geq 60$ twice (that is to say, households can include each such earnings figure twice in the vector from which they choose the highest 35 values). The corresponding increase in the optimal retirement age is 1.57 years. LS [2017] considers raising the payroll tax prior to age 54 and eliminating it thereafter. Here, we attain the similar results, or greater, with a simpler-to-execute change.

Looking at columns 2-4 of Table 4, we see that removing indexation raises per capita consumption. A year of extra work might be thought to represent an increase of lifetime earnings of about 2.5\%. However, a household's lifetime resources are less affected because of unchanged Social Security benefits and spousal earnings. Moreover, earnings near retirement are smaller in present value terms than those from earlier work. Finally, our non-separable utility function causes households to devote extra consumption to years of work, leaving less for the life-long average. Thus, the actual increase in consumption is an order of magnitude less. The change in utility is slightly negative, reflecting lost leisure.

Looking more closely, the average $B(R) \cdot e^{r \cdot R}$ term (recall $\left.(9)\right)$ rises from $\$ 616(1984$ 
dollars) for the simulation of row 1 if we include indexation to $\$ 2753$ without, and to $\$ 3670$ if we allow double counting of earnings past age 60. Recalling that the annual tax wedge is about $\$ 7100$, the offset from the OASI incentive reaches $50-60 \%$.

In summary, changing the way we compute the AIME could incentivize longer careers. Average increases in the retirement age of 1-1.6 years or more seem possible.

\begin{tabular}{|c|c|c|c|c|}
\hline \multicolumn{5}{|c|}{$\begin{array}{l}\text { Table 4. Simulated Change in Average Retirement Age } \\
\text { after Removing Indexing from the AIME Formula }\end{array}$} \\
\hline $\begin{array}{c}\text { Index } \\
\text { Formula } \\
\text { Change } \\
\end{array}$ & $\begin{array}{c}\text { Change } \\
\text { Retirement } \\
\text { Age (Yrs) } \\
\end{array}$ & $\begin{array}{c}\text { Change } \\
\text { Consumption } \\
\text { Per Capita }(\%) \\
\end{array}$ & $\begin{array}{c}\text { Change } \\
\text { Utility } \\
(\%)\end{array}$ & $\begin{array}{c}\text { Change } \\
\text { OASI } \\
\text { Benefit }(\%) \\
\end{array}$ \\
\hline \multicolumn{5}{|c|}{ All Once-Married Couples (1634 Observations) } \\
\hline $\begin{array}{c}\text { Stop Indexing } \\
\text { Earnings Before } 60\end{array}$ & 1.27 & 0.25 & -0.06 & 0.00 \\
\hline $\begin{array}{c}\text { Stop Indexing } \\
\& \text { Double Count } \\
\text { Earnings after } 60\end{array}$ & 1.57 & 0.26 & -0.08 & 0.00 \\
\hline \multicolumn{5}{|c|}{ Couples with High School Educated Male (565 Observations) } \\
\hline $\begin{array}{c}\text { Stop Indexing } \\
\text { Earnings Before } 60\end{array}$ & 1.36 & 0.18 & -0.08 & -2.28 \\
\hline $\begin{array}{c}\text { Stop Indexing } \\
\& \text { Double Count } \\
\text { Earnings after } 60 \\
\end{array}$ & 1.70 & 0.15 & -0.12 & -3.39 \\
\hline \multicolumn{5}{|c|}{ Couples with College Educated Male (429 Observations) } \\
\hline $\begin{array}{c}\text { Stop Indexing } \\
\text { Earnings Before } 60\end{array}$ & 0.83 & 0.31 & -0.01 & 4.29 \\
\hline $\begin{array}{c}\text { Stop Indexing } \\
\& \text { Double Count } \\
\text { Earnings after } 60\end{array}$ & 1.31 & 0.37 & -0.02 & 6.19 \\
\hline
\end{tabular}

Source: see text. Simulations based on the original HRS cohort in all cases.

Potential Contributions to Trust Fund Solvency. This section attempts to relate Table 4 to the OASI Trust Fund's solvency. Our analysis rests heavily on HRS data, which comes from a narrow birth cohort. Thus, computing effects on aggregative government costs and revenues requires approximations.

Our calculations work as follows. We first derive an approximation of total annual Social Security benefits. Assuming an average (male) retirement age of 63 , we sum currentyear OASI benefits for current year retirees, second-year benefits for the same de-trended by annual productivity and work-hours growth, third-year benefits de-trended twice, etc. ${ }^{8}$

8 In Maddison [1991], the U.S. average change in work hours is $1.3 \% / \mathrm{yr}$, and GDP per 
The ratio of OASI and federal income taxes if current retirees work an additional year, divided by the summed benefits, is 0.0370. Our back-of-the-envelope tax-revenue gains, as a fraction of current benefits, come from the product of the preceding ratio and the simulated change in the retirement age from Table 4, column 1, top panel. The changes are then $4.7 \%$ and $5.8 \%$. In other words, the extra tax revenues seem large enough to cover from one-quarter to one-third of the current trust fund shortfall. ${ }^{9}$

Efficiency. Our earlier discussion suggests that existing tax wedges tend to lead to retirement ages lower than the societal optimum. Table 4 allows us to begin to gauge the possible gains from reforms designed explicitly to encourage longer careers.

Evidently the reform of row 1 in the top panel of Table 4 could increase (total) tax revenues enough to cover slightly nmore than $1 / 4$ of the OASI trust fund's shortfall. The double-counting reform of row 2 could cover slightly less than $1 / 3$. Comparing column-3 average household utility losses with rows 1-2 at the top of Table 3, we see they are the same. The policy changes in Table 3, as noted, are almost purely income-effect driven. That is to say, they correspond to lump-sum changes in transfer payments. Thus, the policies in Table 4 match the latter high standard of efficiency.

Discussion. A number of assumptions are implicit in our analysis, as follows.

The model focuses on household incentives. Yet, households are assumed to begin their careers immediately after schooling. For labor supply, only retirement choice is endogenous. Foregoing indexation in the derivation of the AIME would de-emphasize early-career earnings, possibly encouraging later entry into the labor force. However, even non-indexed earnings profiles rise appreciably at first - reflecting strong productivity gains from one-the-job experience. An early start in the labor force gives a long payoff for this human capital. In mid career, on the other hand, firm-specific human capital can be lost in changing jobs, and skills may depreciate rapidly during gaps in employment. Thus, the model's concentration on the age of retirement alone has justification.

A pension determining retirement benefits from the last year of work prior to retirement alone would risk vulnerability to manipulation: an employer could promise a very high ending salary in return for worker concessions at earlier ages. The Social Security system essentially uses a 35-year average of earnings in computing the AIME, however, and the model does not change that.

A fundamental issue is that our simulations disregard disability (though the estimation in Table 1 does make corrections for this (LS [2017])). LS [2012, tab.3] find that HRS self reports of disability explain about $7-15 \%$ of labor force separations through the average age of retirement. The longer careers in Table 4 apply only to the remainder of the work force.

hour is $1.9 \% / y r$, for $1950-1989$. All computations utilize our simple mortality assumptions: males die at 74 , and females at 80 .

9 Many of the extra tax revenues from the policies in Table 4 would accrue through the federal income tax. We are assuming an arrangement could be worked out to route the new revenues to the Social Security trust funds. Precedents include the Greenspan Commission arrangements in the early 1980s and Bush-era Payroll Holiday arrangements in the early 2000 s. 
Implementation of a reform is another important subject. New workers could be initiated into a Social Security program without indexation. But, the benefits for system solvency would not then begin to emerge until their retirement. The same difficulty would apply to benefit reductions if workers already in the the labor force were exempt from system changes. Tax reforms applied only to new workers, in contrast, would have immediate benefits for program solvency. As stated above, all of this paper's analysis compares new and old "steady states," sidestepping transitions between policy regimes.

Finally, the distributional impact of any given reform is of interest as well. The next section turns to this issue.

Distributional Effects of Reform. Tables 2-4 consider separately the impacts on couples with males having high school and college educations.

Table 2 shows the effect of a payroll tax increase is slightly stronger for households in the high school education group. They have slightly longer careers (though they retire at slightly earlier ages), their earnings are more level throughout their careers, and they are less likely to be subject to the payroll-tax cap. ${ }^{10}$

Table 3 shows the high school educated are more strongly affected by uniform Social Security benefit reductions. This reflects the progressivity of the benefit structure, with lower-earners deriving a larger share of their lifetime resources from OASI benefits.

The most interesting distributional outcomes arise in Table 4. With longer, flatter lifetime earnings trajectories, the high school educated have less to gain from removing indexation. Since we (uniformly) re-scale AIME's to hold them constant, on average, after removing indexation, in the end the (average) Social Security benefits of the high school educated fall 2-3.5\%, whereas the college educated enjoy an increase of $4-6 \%$. In terms of utility, the college educated have negligible losses, whereas the high school educated have declines between those of Tables 2-3. With higher overall taxes, the contribution to government revenues from the college educated group, on the other hand, is larger.

\section{Conclusion}

We construct a structural economic model and use HRS and CEX data to estimate its parameters. Then we simulate 3 policies designed to contribute to OASI Trust Fund solvency.

Comparing payroll tax increases to Social Security benefit reductions, neither has a large impact on household retirement ages. The disutility of the benefit reduction case seems lower, but that is partly because our analysis compares long-run balanced growth paths rather than emphasizing transitions after policy changes. Moreover, if the Social Security system has benefits beyond the scope of the model — such as providing economywide annuitization and lessening pressure on other social support programs - reducing the scope of the present Social Security system may not be attractive.

Our main innovation is to consider a third option, of encouraging longer careers. In this paper, we examine a straightforward change in the indexation formula used for

10 The OASI benefit column may seem an anomaly, showing larger effects for the college educated. However, the shorter careers and relatively high late-in-career earnings of the college educated make this possible. And, all of the percentages in column 4 are small. 
computing the AIME. Such a reform would neither lower Social Security benefits nor raise tax rates. Its efficiency (in terms of household utility losses) seems comparable to lumpsum tax and transfer policies - normally considered the premier standard. Simulations show that encouraging longer careers could substantially enhance government revenues providing an additional option for policymakers' planning. 


\section{References}

[1] Banks, James, and Diamond, Peter, "The Base for Direct Taxation," Chapter 6 in J. Mirrlees, S. Adam, T. Besley, R. Blundell, S. Bond, R. Chote, M. Gammie, P. Johnson, G. Myles, and J. Poterba (eds), Dimensions of Tax Design: the Mirrlees Review. Oxford University Press, 2010.

[2] Burtless, Gary, and Quinn, Joseph, "Is Working Longer the Answer for An Aging Workforce?" Center for Retirement Research at Boston College Issue In Brief no. 11, December 2002.

[3] Feldstein, Martin, and Liebman, Jeffrey, "Social security," Chapter 32 in A.J. Auerbach and M. Feldstein (eds), The Handbook of Public Economics, vol. 4. Elsevier, 2002.

[4] French, E., "The Effects of Health, Wealth, and Wages on Labour Supply and Retirement Behavior," Review of Economic Studies 72(2) (April 2005): 395-427.

[5] Goda, Gopi Shah; Shoven, John; and Slavov, Sita, "Removing the Disincentives in Social Security for Long Careers," in Jeffrey Brown, Jeffrey Liebman, and David Wise (eds.), Social Security Policy in a Changing Environment. University of Chicago Press 2009.

[6] Gustman, Alan L., and Steinmeier, Thomas L., "A Structural Retirement Model," Econometrica vol. 54, no. 3 (May 1986): 555-84.

[7] Hurd, Michael, "The Effect of Labor Market Rigidities on the Labor Force Behavior of Older Workers," in (David Wise ed.), Advances in the Economics of Aging. Chicago: The University of Chicago Press, 1996.

[8] Laitner, John, and Silverman, Dan, "Estimating Life-Cycle Parameters from Consumption Behavior at Retirement," (2005) NBER Working Paper 11163.

[9] Laitner, John, and Silverman, Dan, "Consumption, Retirement and Social Security: Evaluating the Efficiency of Reform that Encourages Longer Careers," Journal of Public Economics, 96, no. 7-8 (August 2012): 615-634.

[10] Laitner, John, and Silverman, Dan, "Adjusting the Payroll Tax to Promote Longer Careers," Michigan Retirement Research Center W.P. 2017-363, July 2017.

[11] Maddison, Angus, Dynamic Forces in Capitalist Development. Oxford University Press, 1991.

[12] Rust, John, and, Phelan, Christopher, "How Social Security and Medicare Affect Retirement Behavior in a World of Incomplete Markets," Econometrica 65, no. 4 (July 1997): 781-831. 


\section{Appendix 1}

If $N_{i s}$ is the number of equivalent adults for household $i$ at age $s$, set

$$
\ln \left(N_{i s}\right) \approx 0+N_{i s}-1=\chi_{i s}^{S} \cdot \xi^{S}+\chi_{i s}^{K} \cdot \xi^{K},
$$

where $\chi_{i s}^{S}$ is the indicator function for presence of a spouse at age $s, \xi^{S}$ is the equivalent adult weight for a spouse, $\chi_{i s}^{K}$ is the number of kids in the household, and $\xi^{K}$ is the equivalent adult weight per kid. From the household "Euler equation,"

$$
\frac{X_{i, s+1}}{N_{i, s+1}}=\frac{X_{i s}}{N_{i s}} \cdot e^{\frac{r-\rho}{1-\gamma}}
$$

And, from (7),

$$
X_{i R}=[\omega]^{\frac{\gamma}{1-\gamma}} \cdot X_{i, R-1},
$$

where $s=R$ is the first age $s$ when the household is retired. Assume $N_{i s}$ does not change in the year of retirement. Then combining (A1)-(A3), we have

$$
\begin{aligned}
\Delta \ln \left(X_{i s}\right) & \equiv \ln \left(X_{i, s+1}\right)-\ln \left(X_{i s}\right) \\
& =\frac{r-\rho}{1-\gamma}+\ln \left(N_{i, s+1}-\ln \left(N_{i s}\right)\right. \\
& =\frac{r-\rho}{1-\gamma}+\quad \frac{\xi^{S} \cdot \Delta \chi_{i s}^{S}+\xi^{K} \cdot \Delta \chi_{i s}^{K}}{\frac{\gamma}{1-\gamma} \cdot \ln (\omega) \cdot \Delta \chi_{i s}^{R}} \quad \text { if } s=R+1 \\
& =\frac{r-\rho}{1-\gamma}+\xi^{S} \cdot \Delta \chi_{i s}^{S}+\xi^{K} \cdot \Delta \chi_{i s}^{K}+\frac{\gamma}{1-\gamma} \cdot \ln (\omega) \cdot \Delta \chi_{i s}^{R},
\end{aligned}
$$

where $\chi_{i s}^{R}$ is the indicator function for retirement, and where we have used (A2) in the second line. 
net earning

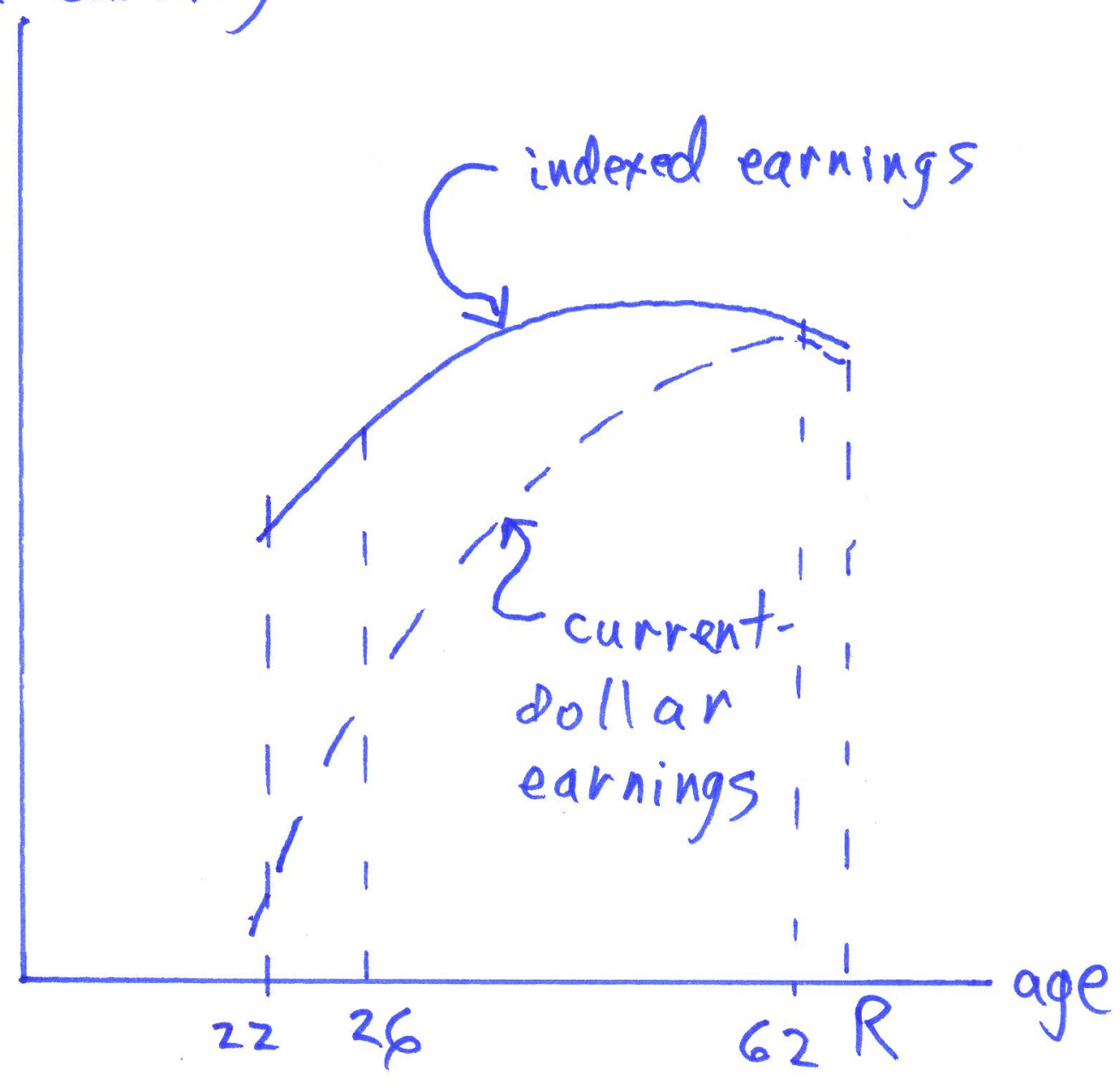

Diagram 1 